\title{
Economic Convergence in the European Union
}

\author{
Ling Yin \\ Jiangnan University \\ George K. Zestos \\ Christopher Newport University \\ Leo Michelis \\ Ryerson Polytechnic University
}

\begin{abstract}
Starting with the Treaty of Rome (1957), the European Union adopted common policies to promote "harmonious economic development and balanced expansion." The paper investigates how successful such policies were, by examining whether there was economic convergence of the real per capita GDP in the $E U$. Two measures of convergence are employed. The first is $\sigma$, which is based on the cross standard deviation of the real per capita GDPs of the EU countries; the second is $\beta$ convergence based on the neoclassical growth model. Both $\sigma$ and $\beta$ were estimated using EU data for the period 1960-1995. The empirical findings

*Corresponding address: Mrs. Ling Yin (Lecturer), School of Business Southern Yangtze University Wuxi, Jiangsu Province, 21063 PR China Tel: +01186-510-5519601, Email: ghhl@Publicl.wx.js.cn Dr. George K. Zestos (Associate Professor), Dept. of Economics and Finance Christopher Newport University, University Place, Newport News, VA 23606, USA Tel: +757-594-7067, Fax : (757) 5947808, E-mail: gzestos@cnu.edu

Dr. Leo Michelis (Associate Professor), Dept. of Economics, Ryerson Polytechnic University, 350 Victoria Street, Toronto, ON, Canada, M5B 2K3 Tel: +416-979-5000 (ext.) 7321, Fax: +416-979-5289, E-mail: Michelis@Ryersou.cc (C)2003-Center for International Economics, Sejong Institution, All Rights Reserved.
\end{abstract}


support the hypothesis of economic convergence within the EU except for the 1980-85 sub-period where weak divergence was indicated.

- JEL Classifications: C1, C3, F15

- Key words: Beta $(\beta)$, Convergence, Sigma $(\sigma)$ convergence, European Union, Nonlinear Least Squares (NLS), Seemingly Unrelated Regressions (SUR)

\section{Introduction}

The successful introduction and establishment of an economic and a monetary union requires similar economic structures without persistent regional disparities in real and monetary conditions. The fulfillment of this requirement has been the focus of policy efforts in the European Union $(E U)$ ever since its official inception as the European Community $(E C)$ with the Treaty of Rome in 1957. European policy makers have adopted economic policies aimed at reducing per capita output and income disparities across its member states. This has taken the form of liberalizing trade in goods and services, allowing for free factor mobility, and devising transfer funds policies in order to help the poorer regions and countries catch up to the richer ones in terms of income and welfare.

Several empirical studies have used time series and cross section data to measure and evaluate economic convergence among countries and regions; e.g., see Sala-i-Martin (1996) and the references therein. A growing empirical literature deals with convergence within the EC. Sapir (1992) used trade data from various sources, for the 1960's, 1970's and 1980's, to evaluate the effects of European integration on trade, welfare and income distribution for twelve EC countries and subsets of it. He finds these effects to be beneficial, but, at the same time, not all regions reaped the same benefits. In some cases, regional disparities were exacerbated. Ben-David (1993) studied the link between trade liberalization and income convergence within the EC. Using country data up to 1985 from various sources, his results support the convergence hypothesis that poor regions tend to grow faster than rich ones. According to Ben-David, most of the convergence occurred in the post world war era, during a period of increased trade liberali-

${ }^{1}$ NUTS (nomenclature des, Unites Territoriales Statistiques) is a standard classification of regions in Europe broken up into three levels. The lower levels give more detailed information (see L. van der Laan 1995 pp. 140). The EU Statistical Bureau drew up these statistical territorial units. 
zation. Neven and Gouyette (1995) assessed convergence in output per capita across 107 EC regions, for the period 1975-90. Their results support the convergence hypothesis for regions in northern Europe but not in southern Europe.

Deuhurst and Mutis-Gaitan (1995) utilized a model of varying convergence rates in GDP per capita among 63 NUTS Level 1 regions of the $E U$ between 1981 and $1991 .{ }^{1}$ Their results indicated that the varying convergence rates for different sub-groups in the sample adjust toward a common equilibrium growth rate. Armstrong (1995) constructed three 85-region data sets drawn from twelve $E U$ member states that span the periods of 1950-70, 1970-90 and 1975-92. His empirical findings strongly supported European convergence with the additional insight that the convergence rates were lower in the 1970s and 1980s than in earlier periods. Cheshire and Carbonaro (1995) examined GDP per capita growth rates for a set of 118 urban regions of the $E U$ for the time period 1980-1990. These authors argued that the estimated convergence rates depend on the conditioning variables in cross section regressions. They reported mixed results depending on the specification of the models. Convergence was confirmed when the conditioning variables were those consistent with the standard neoclassical model, but their results are not robust. The introduction of other variables in cross section regressions such as proxies for scale economies in cities, congestion and other costs in large cities and spatial proximity to other city regions led to evidence of divergence. $^{2}$

Fagerberg and Verspagen (1996) analyzed regional growth in the $E C$ in the postwar period for a sample of 70 regions covering six $E C$ member states. Their empirical results suggested a reversal in the convergence process within the $E C$ that characterized most of the postwar period. The signs of divergence are attributed to different levels of $R \& D$, effort, investment, and support from the $E C$, and the structure of regional GDPs and differences in unemployment. Giannas, Liargovas and Manolas (1999) examined convergence among $E U$ countries for the

\footnotetext{
${ }^{2}$ The three papers referred to in this paragraph are contained in an excellent volume edited by Armstrong and Vickerman (1995) entitled: Convergence and Divergence Among European Regions. Other papers in this volume examine regional convergence or divergence from other interesting perspectives such as convergence of regional unemployment rates, convergence in factor prices and techniques of production. Few papers considered convergence in other aspects of regional labour markets such as demographics, labour mobility and participation rates.

${ }^{3}$ The coefficient of variation of a set of numbers is the standard deviation (sigma) over the mean of the numbers. Unlike sigma, the coefficient of variation is a relative measure of convergence and free of units of measurement, this constitutes an advantage over sigma. It just happened for this study the two measures of convergence gave similar results.
} 
period of 1970-1990 by considering not only economic indicators but also social and quality of life indicators. The authors pointed out that social and quality of life variables such as crime rates, pollution, public services, health care and infrastructure among others are equally important as economic variables in determining the well being of individuals. Their main tool of analysis was the Coefficient of Variation $(\mathrm{CV})$ constructed for eight economic and quality of life indicators for each of the three sub-groups of $E U$ countries. ${ }^{3}$ To determine real convergence among the three $E U$ sub-groups of countries they constructed a weighted average $C V$ of the eight $C V s$ through time particularly for the years 1970, 1975, 1980, 1985 and 1990. According to this broadly defined measure of convergence, most countries converged during the period 1970-75, diverged in the period 198085 and started converging again after 1985.

The purpose of this study is an empirical investigation of the real capita GDP convergence among all the 15 current $E U$ countries, EU15, and subsets of them, using the concepts of $\sigma$-convergence and $\beta$-convergence, the latter introduced by Barro and Sala-i-Martin $(1991,1992)$. The former concept examines the behavior of the cross sectional standard deviation of real per capita GDPs over time, a measure that has been used as an indicators of economic convergence by the $E U$ authorities. The latter concept derives from the transitional dynamics of the standard neoclassical growth model and focuses on the existence or lack of mean reversion in GDP growth rates in a cross section of countries.

Two aspects make this study different from other studies in the literature. First, we expand the sample period from 1960 to 1995 . Given that convergence is a dynamic phenomenon, expanding the sample size with more recent information is likely to produce more powerful results. Second, in contrast to existing studies, we examine convergence for all the 15 current members of the $E U$, following the latest round of expansion to include Austria, Sweden and Finland. This provides additional information on the effects of $E U$ widening on the convergence process.

The rest of the paper is organized as follows. Section 2 is devoted to the methodology. Section 3 explains the data to be used in the study. Sections 4 and 5 discuss the empirical results for $\sigma$-convergence and $\beta$-convergence respectively, for all the EU15 countries over the sample period 1960-95. Section 6 analyzes the empirical results for convergence within and between sub-groups of the $E U$. Section 7 compares the degree of convergence within and between five continents and two trade blocs. Section 8 concludes the paper. 


\section{Methodology}

Two measures of convergence are employed in this study. The first is sigma $(\sigma)$ convergence based on the cross sectional standard deviation of the real per capita $G D P s$ among a group of countries. In this study we also examine the $C V$. The $C V$ and $\sigma$ for the real per capita GDPs were calculated for the EU15 countries and for smaller subsets of countries for the entire sample study period 1960-1995. A decline in $\sigma$ and the $C V$ for prolonged time is evidence of convergence. On the other hand, an increase in the two measures indicates divergence in the real per capita GDPs among the $E U$ countries.

Another well-known measure of convergence in the economic literature is beta $(\beta)$ convergence. This measure of convergence is based on the neoclassical growth model of Ramsey (1928), Solow (1956), and Koopmans (1966). It was introduced and popularized in the empirical growth literature by Barro (1991) and Barro and Sala-i-Martin $(1991,1992)$. In the neoclassical growth model, the parameter $\beta$ captures the rate at which a country's real per capita GDP approaches its steady state rate of growth; i.e., $\beta$ is a speed of adjustment parameter. ${ }^{4}$ Since rich countries are endowed with more capital than poor countries, they are expected to experience diminishing returns to capital before the poor countries. This condition, assuming other things are held constant and all countries have the same steady state real per capita GDP, permits the poor countries to grow faster than the rich ones, eventually catching up with them. If, however, the steady state per capita GDPs among countries are different, then $\beta$-convergence will not be attained.

If the steady state preferences and technology among countries are the same, $\beta$ can be estimated in a simple regression equation based on the average relation of the initial values of the cross sectional real per capita GDPs and the rates of growth of the countries' real per capita $G D P$ within a given time period. In this case, the $\beta$ measure is known as absolute or unconditional convergence. On the other hand, if the steady state characteristics of the economies are different, $\beta$ can still be estimated. To estimate $\beta$ in this case additional relevant explanatory variables must be included in the cross-country regression equation in order to account for the variation in the steady state per capita income and the exogenous labor

\footnotetext{
${ }^{4}$ Despite some controversy, this classical approach to convergence analysis is still the most popular method in the empirical literature. Two alternative approaches to convergence have been proposed by Quah (1993) and Evans (1996) respectively. No attempt is made in this paper to broaden the debate on the merits of each approach.
} 
augmenting technological progress among countries. In this case the esti-mated $\beta$ is known as a measure of conditional convergence.

Convergence of either type requires a negative relationship between the initial year average cross sectional per capita income or $(G D P)$ and the average rate of growth of the countries' real per capita $G D P$ within a specified time interval. This is the hypothesis to be investigated in this study. Economic divergence among countries real per capita GDPs is supported by some endogenous growth models. These models assume nonconvexity in production, which can be caused from human capital accumulation entering as an input in the production function of firms located in high per capita income countries. This phenomenon creates positive production externalities allowing such firms to avoid diminishing returns to capital. In this case, rich countries tend to grow faster than poor countries. Romer (1986), Krugman and Venables (1996), and Ben-David and Lowey (2000) introduced endogenous growth models that predict economic divergence among countries. This constitutes the competing alternative hypothesis in this study.

Equation (1) is based on the neoclassical growth model and allows for the estimation of $\beta$ as a measure of absolute convergence:

$$
\frac{1}{T} \ln \frac{y_{i, t}}{y_{i, t-T}}=\alpha-\frac{1-e^{-\beta T}}{T} \ln y_{i, t-T}+U_{i t}
$$

where :

$y_{i, t}=$ the real per capita GDP for country $i$ in year $t$.

$y_{i, t-T}=$ the initial period real per capita GDP for country $i$.

$T$ =the length of the time interval, in years.

$U_{i t}=$ the error term and

ln =natural logarithm.

The dependent variable in equation (1) is the average rate of growth for country $i$ within an interval of $T$ years.

A model for conditional convergence extends equation (1) to include a number of other variables in order to keep the steady state characteristics of the economies constant:

$$
\frac{1}{T} \ln \frac{y_{i, t}}{y_{i, t-T}}=\alpha-\frac{1-e^{-\beta T}}{T} \ln y_{i, t-T}+\Phi X_{i, t}+U i t
$$


where $X_{i, i}=\mathrm{a}$ set of exogenous variables maintaining the steady state characteristics of the economies constant, and $\phi$ is a set of unknown coefficients. If $\beta$ convergence is empirically supported in equation (2), this will not necessarily imply that poor countries' real per capita GDP converges to the real per capita $G D P$ of the rich countries. It simply means that if all steady state characteristics of the economies could be held constant, then and only then would countries with low initial real per capita GDP grow faster than rich countries, thus catching up with them.

The two concepts of $\sigma$-convergence and $\beta$-convergence are closely related. $\beta$-convergence measures the average speed at which poor economies approach, in terms of real per capita GDP, the rich countries within a specified time interval. On the other hand, $\sigma$-convergence indicates whether the cross sectional variation of the real per capita GDPs among a group of countries decreases over time. In most cases, it is expected that the two measures will be in agreement, either indicating convergence or divergence. It is possible, however, that the two measures may indicate conflicting results. For example, it is possible that the $\beta$ measure may suggest a long run convergence, but random shocks captured by an increase of the error terms $u_{i t}$ in equations (1) or (2) can increase $\sigma$ to erroneously indicate divergence. If both $\beta$ and $\sigma$ indicate economic divergence among countries this will be evidence for support of the competing hypothesis suggested by the endogenous growth models.

\section{Data}

A time series data set of 36 annual observations was constructed for the period 1960-1995 for all EU15 countries in several variables. ${ }^{5}$ The variables are:

1. Real per capita $G D P\left(y_{i}\right)$.

2. Average private nominal investment to nominal GDP ratio.

3. Average population growth rate.

4. Average inflation rate.

5. Average nominal government expenditures to nominal GDP ratio.

\footnotetext{
${ }^{5}$ The fifteen countries are: Belgium, Denmark, Germany, Greece, Spain, France. Ireland, Italy, Luxembourg, Netherlands, Austria, Portugal, Finland, Sweden, and UK. All economic data are from the International Financial Statistics (IFS) electronic database (CD-ROM) published by the International Monetary Fund.
} 
6. A regional dummy is also used which takes the value of one for the southern European countries (Greece, Spain, and Portugal), and zero for the remaining $E U$ countries.

A second set of data for socio-political and policy variables was also constructed for all $E U$ countries. These variables were always considered by economists to play a crucial role for economic development and growth. Such variables have been used in several studies, as in Barro (1991, 1996), Knack and Keefer (1997), and Gastil (1990) among others. Socio-political and policy variables, however, create positive or negative externalities that influence economic growth and the rate of economic convergence or divergence among countries. In this study three such variables are included, the first two capture political and social stability and the third one is a policy variable related to the quality of the labor force in terms of the literacy rate. These variables are as follows:

1. Average number of annual cabinet changes - these are major annual changes in the cabinet of the ruling party.

2. Riots - the average number of riots per year for the period.

3. Literacy rate - measured as the initial annual percent rate for the period. ${ }^{6}$

The average number of annual cabinet changes is used as a proxy for reduced corruption and bureaucratic inefficiencies. As such, this variable is expected to have a positive effect on economic growth. Riots are sources of political instability and are expected to have a negative impact on growth. The literacy rate is an indicator of a country's stock of human capital and it is expected to have a positive effect on real per capita GDP growth. To the extent that annual cabinet changes, (riots) and the literacy rate increase (decrease) proportionately more in poor countries than in rich ones, they also contribute to economic convergence.

We concur with the view of a referee that, among the three variables, the literacy rate should be treated as a policy variable related to the level of per capita income since poor countries cannot afford high levels of educational spending. Given this interpretation, the two socio-political variables and the one policy variable were

\footnotetext{
${ }^{6}$ The socio-political, institutional and policy data are from, "Banks Cross-National Time Series Data," an institutional, social, and political database offered by Banner Software Inc.

${ }^{7}$ The thirteen variables were cabinet changes, riots, literacy rates, war, purges, black market rates, assassinations strikes, crises, revolutions, demonstrations, coup d'etats, and constitutional changes.
} 
selected from a set of thirteen such variables based on the overall effect of each variable on the rate of growth. ${ }^{7}$ We excluded variables from this set which were highly collinear and variables which turned out to be consistently statistically insignificant. We also excluded variables such as revolutions, which for the 19601995 sample period were irrelevant to the $E U$ countries.

We expect the literacy rate to increase faster in the poorer $E U$ countries, since rich $E U$ countries had a highly literate population even before the 1960s. Similarly, cabinet changes were more prevalent in less developed $E U$ countries like the Mediterranean countries, which gradually and steadily have been transformed to stable democracies. Lastly, riots were declining faster in the relatively less developed Mediterranean countries, as these countries gradually solidified democracy and their people had a lesser need to express their anger and dissatisfaction to governmental policies with riots. We therefore expect the three variables to have a positive effect on the rate of convergence in the $E U$ countries.

Based on these economic and non-economic variables, two separate data sets were created. One data set was constructed by dividing the original data in seven sub-periods of five years each, i.e., 1960-65, 1965-70, 1970-75, 1975-80, 1980-85, 1985-90, and 1990-95, thus creating the five year period real per capita GDP average growth rate, and the averages of all other relevant variables. Similarly for the second subset, we divided the entire sample in ten-year sub-periods, i.e., we created three ten-year sub-periods and a smaller sub-period of five years. These sub-periods are 1960-70, 1970-80, 1980-90 and 1990-95. Our empirical work is based on these two data sets. The two different sub-period data sets were constructed in order to study the sensitivity of the results to the interval width choice of the sub-period. Particularly to study carefully the rate of economic growth and the rate of convergence/divergence of $E U$ countries within both the five and ten year subintervals.

All nominal variables were first expressed in 1990 national currency units, and thereafter converted to 1990 US dollars using the official exchange rates. The same nominal variables were also transformed to 1990 US dollars using the Purchasing Power Parity (PPP) rates. The entire study was carried out using the

\footnotetext{
${ }^{8}$ Conversion of foreign national incomes or GDPs into another currency using the official exchange rate have found not to be very accurate. Official exchange rates do not take into consideration relative national commodity price differences. Purchasing Power Parity rates are constructed to correct relative national price differences. It turns out that the two exchange rates are not independent from each other; consequently the results in our study are similar and it does not make a difference which exchange rates are employed.
} 
official exchange rates and the PPP rates. We report only the results based on the official exchange rates since the results based on the PPP are similar. ${ }^{8}$

It should be noted that not all countries were members of the $E U$ for the entire 1960-1995 period. However, some countries signed agreements leading to gradual trade liberalization with the $E C$. This is the case for Greece and the European Free Trade Association (EFTA) countries most of which eventually joined the $E U$. These developments contributed to the process of $E U$ integration before the actual date of a country's official membership. Further, in respect of the first and second enlargements of the $E U$ described below, economic integration can be justified in term of these countries' similarity of economic structures, trade and geographic proximity. ${ }^{9}$ With this caveat in mind, we proceed to analyze economic convergence within the $E U$.

\section{Sigma Convergence}

Figure 1 presents the cross sectional standard deviations $(\sigma)$ of the logarithms of the real per capita $G D P$ of four different $E U$ groups of countries. The $E U 6$ consists of the original six $E U$ countries, Belgium, France, Germany, Italy, Luxembourg,

Figure 1. Dispersion of Real Per Capita GDP across EU Countries, 1960-1995

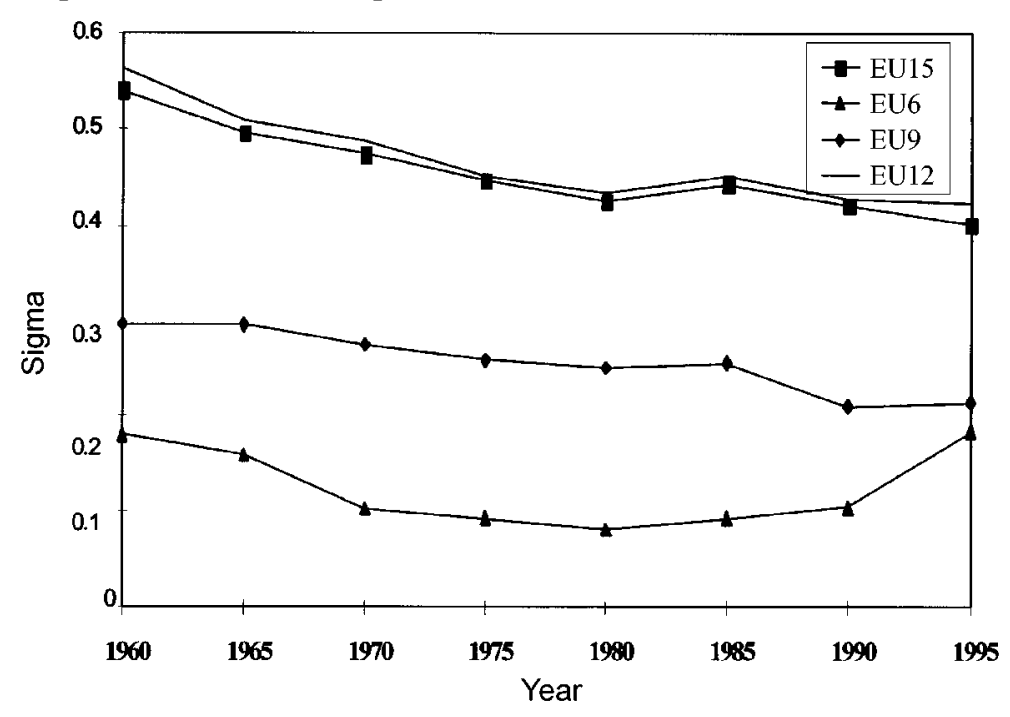

Note: GDP dispersion is measured by the unweighted cross-sectional standard deviation of the log of the real per capita GDP

${ }^{9} \mathrm{We}$ are indebted to an anonymous referee for pointing out this argument to us. 
Figure 2. Average Growth Rate Across all EU 15 Countries

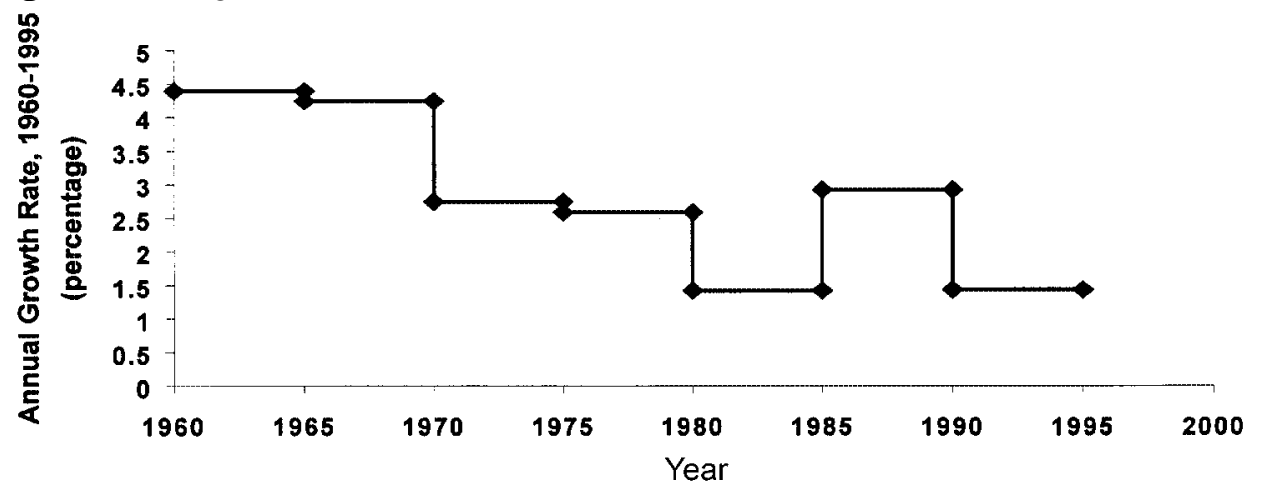

and the Netherlands. The EU9 is composed of the EU6 and Denmark, Ireland and the $U K$, which joined in 1973 . The EU12 consists of the EU9 plus the three Mediterranean countries, Greece (which became the $10^{\text {th }}$ member in 1981), and Portugal and Spain (which joined in 1986). Lastly, the EU15 includes EU12 and Austria, Finland and Sweden, which were the last three countries to join the $E U$ in 1995.

As seen in Figure 1, the cross sectional standard deviations of the real per capita GDPs for EU15, EU9 and EU12 have declined over the sample period 1960-1995. An exception is the sub-group of the original EU6 countries for which $\sigma$ declined the first two decades, but increased the last fifteen years, while it still remained the lowest one. It is also clear from Figure 1 that there is a tendency for $\sigma$-convergence among the four $E U$ groups of countries. While $\sigma$ has been rising since 1980 within the $E U 6$, it has declined for the other $E U$ groups. A possible explanation of this phenomenon is that $E U$ enlargement was accomplished at the cost of interrupting integration of the existing members. There appears to be a halt in the "deepening" of further integration in the original EU6 countries. Similar findings were reported by Jacquemin and Sapir (1988) and Lloyd (1992).

These authors found that further integration between new and old $E U$ members in terms of import shares during the 1973 and 1986 enlargements of the $E U$ occurred at the cost of divergence in the import shares from within the old $E U$ countries. While there was a downward trend in $\sigma$ for EU15, EU12, and EU9 during the entire sample period of 1960-1995, for the sub-period 1980-85, $\sigma$ increased slightly in every sub-group of $E U$ countries. An explanation for this evidence of divergence of the $E U$ economies is the sluggish economic growth of the $E U$ during this period. This is indicated in Figure 2, which shows the average 
growth rate of all $E U 15$ countries during the five-year sub-periods of the sample. ${ }^{10}$

The $E U$ countries often experienced difficulty in promoting higher levels of integration during periods of recession. The main reason for this is that national governments focus mainly on combating domestic unemployment rather than pursuing common programs aiming at further integration. We conclude that there exists evidence of $\sigma$ convergence in the $E U$ countries. Such type of convergence is expected to continue as the $E U$ is advancing into higher levels of integration with the completion of the $E M U$ and the enhanced role of the common policies aiming to promote further integration. Evidence of $\sigma$-convergence, however, is devoid of any explanations to why such convergence takes place. One can only speculate the reasons leading to the convergence. Here, we suggest that $E U$ programs and policy measures led to economic integration. More important of these is trade liberalization and the structural policies aiming to make the economies more similar. Other authors offered other reasons such as the similarity of these economies, particularly in the concentration on trade in manufactures and the proximity of the $E U$ countries to each other.

\section{Beta Convergence}

In this section, we present and discuss empirical results on absolute and conditional convergence. Figure 3 plots the logarithm of the 1960 real per capita GDP

Figure 3. Convergence of Per Capita GDP across all EU 15 Countries: Growth Rate fron 1960 to 1995 vs. 1960 Per Capital GDP

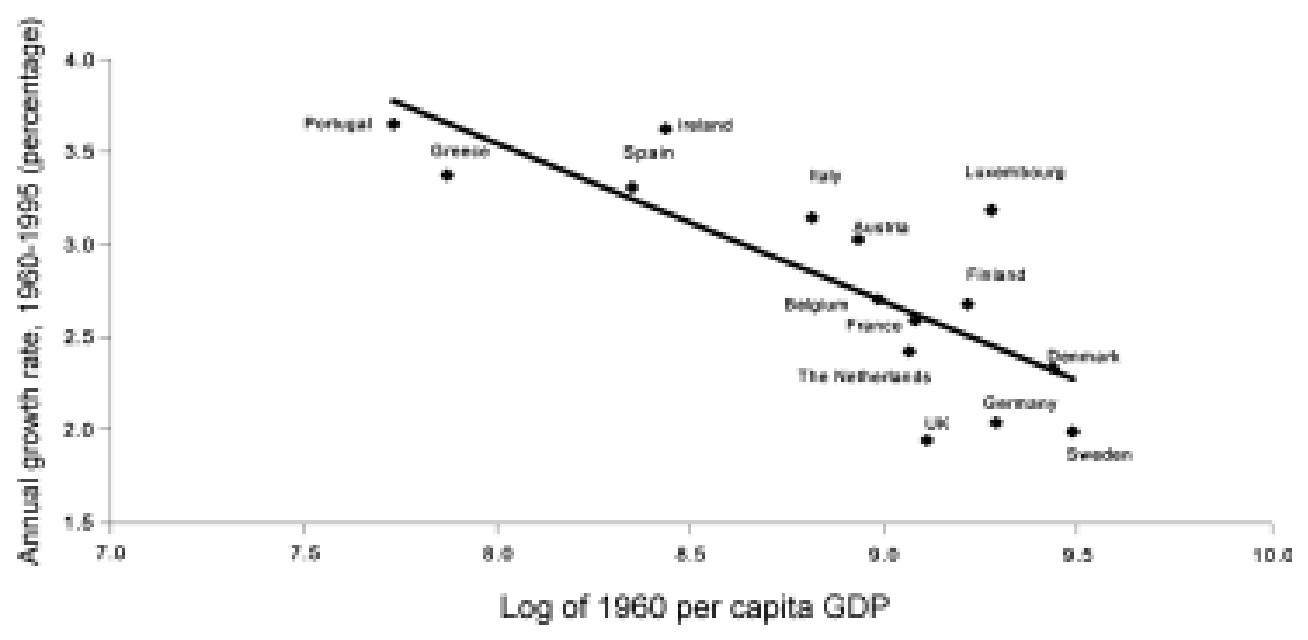

${ }^{10}$ Such low rate of growth reoccurred in one more sub-period, during the first half of the 1990s. 
Table 1A. Absolute and Conditional Convergence in the European Union

\begin{tabular}{|c|c|c|c|c|c|c|c|c|}
\hline \multicolumn{9}{|c|}{ Regression for Real Per Capita GDP Growth across All 15 EU Countries } \\
\hline \multirow[t]{2}{*}{$\begin{array}{l}\text { Period } \\
\text { Model }\end{array}$} & \multicolumn{2}{|c|}{ Basic Equation } & \multicolumn{2}{|c|}{$\begin{array}{l}\text { Equation with } \\
\text { other Economic } \\
\text { Variables } \\
\text { (2) }\end{array}$} & \multicolumn{2}{|c|}{$\begin{array}{c}\text { Equations with } \\
\text { Dummy and Eco- } \\
\text { nomic Variables } \\
\text { (3) }\end{array}$} & \multicolumn{2}{|c|}{$\begin{array}{c}\text { Equations with } \\
\text { Dummy, Economic } \\
\text { Socio-Political and } \\
\text { Policy Variables } \\
\text { (4) }\end{array}$} \\
\hline & $\beta$ & $\mathrm{R}^{2}$ & $\beta$ & $\mathrm{R}^{2}$ & $\beta$ & $\mathrm{R}^{2}$ & $\beta$ & $\mathrm{R}^{2}$ \\
\hline \multirow{3}{*}{$1960-95$} & {$[\mathrm{t}]$} & [ SER] & {$[\mathrm{t}]$} & [SER] & {$[\mathrm{t}]$} & [SER] & {$[\mathrm{t}]$} & [SER ] \\
\hline & 0.01 & {$[.63]$} & .019 & .79 & .018 & .79 & 0.02 & 0.81 \\
\hline & {$[3.89] * * *$} & [.004] & {$[2.66]^{* *}$} & [.003] & {$[2.38]^{* *}$} & [0.003] & {$[1.96] * *$} & [0.004] \\
\hline \multirow{2}{*}{$1960-65$} & .019 & .45 & .016 & .8 & -.0006 & .92 & -.001 & .92 \\
\hline & $3.17 * * *$ & {$[.010]$} & {$[2.4]^{*}$} & [.009] & {$[-.08]$} & {$[.006]$} & {$[-.08]$} & {$[.006]$} \\
\hline \multirow{2}{*}{$1965-70$} & .0107 & .17 & .016 & .64 & .034 & .74 & .019 & .98 \\
\hline & [1.6] & {$[.001]$} & [1.9] & [.011] & {$[2.17]^{*}$} & [.01] & {$[3.79]^{* *}$} & {$[.003]$} \\
\hline \multirow{2}{*}{$1970-75$} & .012 & .40 & .008 & .58 & -.001 & .65 & .011 & .72 \\
\hline & {$[2.8]^{* *}$} & {$[.007]$} & {$[.90]$} & [.008] & [-.093] & {$[.007]$} & [1.64] & {$[.005]$} \\
\hline \multirow{2}{*}{$1975-80$} & .011 & .21 & .018 & .63 & .004 & .81 & .039 & .88 \\
\hline & {$[1.8]^{*}$} & [.009] & [1.58] & [.008] & {$[3.07]^{* *}$} & {$[.006]$} & {$[4.19]^{* * *}$} & {$[.005]$} \\
\hline \multirow{2}{*}{$1980-85$} & -.008 & .30 & -.01 & .33 & -.007 & .35 & -.008 & .81 \\
\hline & {$[-2.4]^{*}$} & [.005] & {$[-1.29]$} & [.006] & {$[-.64]$} & [.007] & {$[-1.81]$} & [.003] \\
\hline \multirow{2}{*}{$1985-90$} & .012 & .20 & .025 & .75 & .029 & .76 & .036 & .94 \\
\hline & {$[1.8]^{*}$} & [.011] & {$[3.2]^{* *}$} & [.007] & {$[2.47]^{* *}$} & $.008]$ & {$[4.71]^{* * *}$} & [.004] \\
\hline \multirow{2}{*}{$1990-95$} & .015 & .09 & .03 & .28 & .05 & .36 & .057 & .47 \\
\hline & [1.1] & [.02] & [1.2] & {$[.02]$} & [1.45] & [.008] & {$[1.1]^{*}$} & {$[.02]$} \\
\hline
\end{tabular}

Note: Numbers in brackets are $t$-ratios. $* * *, * *, *$ indicates significance at the $1 \%, 5 \%$, and $10 \%$ level respectively.

against the average annual growth rate of the real per capita GDP over the 19601995 period for the EU15 countries. ${ }^{11}$ The graph supports the hypothesis of absolute convergence. It is clear from Figure 3 that there exists a negative relation between the 1960 real per capita GDP and the rate of growth of the economies during the sample period. Countries with low levels of initial per capita GDP like Portugal, Greece, Spain and Ireland, achieved the highest rate of growth for the entire period. In contrast, countries such as Germany, Sweden, $U K$ and Denmark, which began with high initial year per capita GDP attained low rates of growth. The negative relation between the rate of growth and the initial year of the period real per capita $G D P$ is also indicated by the relatively high and negative correlation coefficient (-.79) of the two variables.

In the remainder of this section, we use regression techniques to investigate the

\footnotetext{
${ }^{11}$ All $E U$ member countries per capita GDPs were transformed to real 1990 US dollars.
} 
Table 1B. SUR Beta Estimates for Absolute and Conditional Convergence: Dependent Variable: Growth of Real Per Capita GDP

\begin{tabular}{|c|c|c|c|c|}
\hline Model & 1 & 2 & 3 & 4 \\
\hline $\begin{array}{c}\text { Joint Seven Sub Periods } \\
\beta\end{array}$ & $\begin{array}{c}0.017 \\
{[7.4]^{* * * *}}\end{array}$ & $\begin{array}{c}0.023 \\
{[10.91]^{* * *}}\end{array}$ & $\begin{array}{c}0.026 \\
{[9.86]^{* * *}}\end{array}$ & $\begin{array}{c}0.019 \\
{[8.68]^{* * *}}\end{array}$ \\
\hline $\begin{array}{c}\text { Joint Seven Sub Periods }^{2} \\
\beta\end{array}$ & $\begin{array}{c}0.01 \\
{[5.43]^{* * *}}\end{array}$ & $\begin{array}{c}0.015 \\
{[8.87]^{* * *}}\end{array}$ & $\begin{array}{c}0.018 \\
{[7.66]^{* * *}}\end{array}$ & $\begin{array}{c}0.022 \\
{[7.24] * * *}\end{array}$ \\
\hline $\begin{array}{c}\chi^{2} \text { statistics (6 d. f.) } \\
\text { p-values }\end{array}$ & $\begin{array}{r}55.86 \\
0.00\end{array}$ & $\begin{array}{r}38.03 \\
0.00\end{array}$ & $\begin{array}{r}39.49 \\
0.00\end{array}$ & $\begin{array}{r}56.94 \\
0.00\end{array}$ \\
\hline Number of observations & $\begin{array}{c}(15,15,15,15, \\
15,15,15)\end{array}$ & $\begin{array}{c}(12,12,15,15 \\
15,15,15)\end{array}$ & $\begin{array}{c}(12,12,15,15 \\
15,15,15)\end{array}$ & $\begin{array}{c}(11,12,15,15, \\
15,13,13)\end{array}$ \\
\hline
\end{tabular}

Notes: Numbers in brackets are t-statistics. $* * *, * *, *$ indicate significance at the $1 \%, 5 \%$ and $10 \%$ level respectively.

${ }^{1}$ Joint estimation of all 7 sub-periods using the SUR method by keeping all the coefficients the same.

${ }^{2}$ Joint estimation of all 7 sub-periods using the SUR method by keeping $\beta$ the same and allowing all other coefficients to differ.

${ }^{3}$ Due to lack of data, where the number of observation is 11 excluded are the UK, France, Luxembourg and Portugal; where the number of observations is 12 excluded are France, Luxembourg and Portugal; where the number of observations is 13 excluded are France and Luxembourg.

hypothesis of convergence in the EU. First we present results for the five-year subperiods and then we proceed with the results of the ten-year sub-periods.

\section{A. Beta Convergence Using the Five Years Sub-periods}

Table 1A provides Nonlinear Least Squares (NLS) results from estimating four models based on equations (1) and (2). The estimation is for the entire data set (1960-1995) and the seven-year sub-periods constructed data for all EU15 countries. The dependent variable in all four regressions is the average rate of growth of the real per capita cross sectional GDP for all EU15 countries. The results of four different estimated equations are reported in columns (1) to (4). The estimated value of $\beta$ and its t statistic are reported along with two measures of goodness of fit of the regression, the coefficient of determination, $R^{2}$, and the standard error of the regression (SER). ${ }^{12}$ Column 1 reports the results from estimating equation (1), the basic regression. In this model, the only independent variable is the initial year real per capita GDP. The estimated value of $\beta$ for the entire period reported in the first row is .01 and is significant at the $1 \%$ level. Thus, assuming that the $E U$ economies are similar in terms of steady state charac-

${ }^{12}$ Where $\mathrm{SER}=\sqrt{\frac{S(y-\hat{y})^{2}}{n-k-1}}, \mathrm{n}$ is the number of observations in the sample, and $\mathrm{k}$ is the number of independent variables included in the regression. 
teristics, they were converging to a common real per capita $G D P$ at an annual rate of one percent over the 1960-1995 sample period. This is the rate of absolute or unconditional convergence.

In column (2), the model is extended to include four additional economic explanatory variables: private investment to GDP ratio, population growth rate, inflation rate, and government expenditures to $G D P$ ratio. All four variables are averages for the period. To save space and keep the focus on the convergence parameter, we report only the estimated $\beta$ value, its $t$-statistic, $R^{2}$ and SER. ${ }^{13}$ For this model, the estimated value of $\beta$ for the entire sample is statistically significant and equal to .019 , i.e., almost double the estimated value of $\beta$ found in the basic equation. Thus, if the four economic explanatory variables in this model other than the initial GDPs were held constant across all countries, the EU15 countries would have converged at an annual rate of 1.9 percent. Column 3 reports the empirical results for the case where a regional dummy variable was added to the model to account for possible different steady state characteristics of the three southern $E U$ countries, Greece, Portugal and Spain. In this case, the estimated $\beta$ is .018 and significant at the $5 \%$ level. ${ }^{14}$ In column (4), the model was reestimated by including three additional socio-political and policy variables: cabinet changes, riots and the literacy rate. In this case, the estimated $\beta$ coefficient is still .019 and remained statistically significant at the $5 \%$ level. ${ }^{15}$ The results of the estimated regressions of the 5 year sub-periods seem plausible and in agreement with the findings of $\sigma$ convergence. For example, in the 1980-85 sub-period the estimated value of $\beta$ is negative indicating economic divergence, a result consistent with an increasing $\sigma$ presented in the previous section for the same sub-period.

The four models were also estimated with the method of Seemingly Unrelated

\footnotetext{
${ }^{13}$ The complete table with the results can be available from the authors. We omitted this table because the entire table with all the detailed results is bulky.

${ }^{14}$ The value of $\beta$ based on the estimation of this model remained practically the same, this means that three Mediterranean countries are similar in their steady state properties with the rest of the $E U$ countries. At least this is what the estimated Model 3 suggests.

${ }^{15}$ Models 2, 3, and 4 were first estimated with an additional explanatory variable, trade openness, which is defined as exports plus imports divided by GDP. When the model was estimated with trade openness $\beta$ was substantially larger but some of the independent variables were entering the regression with the theoretically incorrect expected sign. It was pointed out to us by one of the referees that trade openness is endogenous in the sense that an increase in trade openess is the result of the trade agreements that led to the reduction or elimination of trade barriers among the EU member countries. We dropped this variable and observed improvement in the results. We also dropped trade openness in all the other models estimated in this study. While most of the results did not change substantially, we are certain that there was a definite inprovement in the estimation. We are thankful for this suggestion.
} 
Regressions (SUR) with seven equations, one for each 5-year sub-period. The SUR method is appropriate when it can be assumed that the cross equation errors are correlated. In this study, such an assumption seems reasonable since the same equation is estimated for the same group of countries for all the five-year consecutive sub-periods from 1960 to 1995 . It is possible that an omitted variable with correlated values causes the correlation in the cross equation errors. The empirical results using this method are reported in Table 1B. The system was first estimated by restricting all the coefficients to be the same across the seven sub-periods. In this case, the estimated values of $\beta$ for the four models are $0.017,0.023,0.026$, and 0.019 respectively. The parameter $\beta$ was highly significant in all four estimated models discussed above.

The model was reestimated by allowing different values in the coefficients of all the variables except for $\beta$. This less restricted model yielded highly significant $\beta$ coefficients for the four estimated models of $0.01,0.015,0.018$, and 0.022 respectively. The calculated statistic rejected the null hypothesis for equality of the $\beta$ coefficients across the seven sub-periods at any plausible level of significance as it is indicated by the zero $p$-values. These results are consistent with the NLS results reported in Table 1A, which show the values of $\beta$ to differ across subperiods.

\section{B. Beta Convergence Using the Ten Years Sub-periods}

Table 2, reports the NLS results for three different regression models estimated for each of the three 10 year sub-periods, 1960-1970, 1970-1980, 1980-1990, and for the entire sample period 1960-1995. The dependent variable in the three estimated regression models for each period is the average rate of growth of the cross sectional real per capita GDP for the EU15 countries. The first model is equation (1), the second model extends the first by including the four additional economic variables. Lastly, the third model extends the second model by including a dummy variable for the three southern $E U$ countries. As seen from Table $2, \beta$ is significant in eleven out of twelve equations and is always positive indicating convergence. ${ }^{16}$ The range of the $\beta$ values in these regressions is from .002 to .025 , the most common values being between .01 and .02 . Most of the independent

\footnotetext{
${ }^{16}$ These results are different from the 5-year sub-periods reported in Table $1 \mathrm{~A}$ where $\beta$ in a few regressions turned out to be negative suggesting divergence. In Table $2, \beta$ is always positive. It is clear from this analysis that the selection of the large 10-year sub-periods does not reveal all of the information regarding convergence within this choice of the longer interval sub-periods.
} 
Table 2. Absolute and Conditional Convergence in the EU15 Dependent Variable: Growth of Real Per Capita GDP

\begin{tabular}{|c|c|c|c|c|c|c|}
\hline Period & 1960-70 & 1960-70 & $1960-70$ & 1970-80 & 1970-80 & $1970-80$ \\
\hline Model & (1) & (2) & (3) & (1) & (2) & (3) \\
\hline \multirow{2}{*}{ Constant } & 0.16 & 0.16 & 0.15 & 0.12 & 0.09 & 0.17 \\
\hline & {$[4.21] * * *$} & {$[4.96]^{* * *}$} & {$[2.3] *$} & {$[4.61] * * *$} & {$[1.56]$} & {$[2.97] * *$} \\
\hline \multirow{2}{*}{ Beta } & 0.014 & 0.02 & 0.02 & 0.011 & 0.01 & 0.02 \\
\hline & {$[2.90] * *$} & {$[5.07] * * *$} & {$[2.4] *$} & {$[3.45] * * *$} & {$[2.16] *$} & {$[3.35] * *$} \\
\hline \multirow{2}{*}{ Investment/GDP } & & 0.23 & 0.23 & & 0.17 & 0.17 \\
\hline & & {$[3.18]^{* *}$} & [2.92] ** & & {$[3.1] * *$} & {$[3.85] * * *$} \\
\hline \multirow{2}{*}{$\begin{array}{l}\text { Population } \\
\text { growth rate }\end{array}$} & & -0.035 & -0.04 & & -0.06 & -0.06 \\
\hline & & {$[-0.57]$} & {$[-0.54]$} & & {$[-1.96]^{*}$} & {$[-2.5]^{* *}$} \\
\hline \multirow{2}{*}{ Inflation rate } & & 0.007 & 0.006 & & -0.001 & -0.002 \\
\hline & & {$[0.78]$} & {$[0.63]$} & & {$[0.63]$} & {$[-1.06]$} \\
\hline \multirow{2}{*}{$\begin{array}{l}\text { Gov. Expenditures/ } \\
\text { GDP }\end{array}$} & & -0.04 & -0.03 & & 0.01 & -0.015 \\
\hline & & {$[-1.01]$} & {$[-0.7]$} & & {$[0.78]$} & {$[-0.85]$} \\
\hline Regional dummy & & & $\begin{array}{l}0.002 \\
{[0.19]}\end{array}$ & & & $\begin{array}{l}-0.01 \\
{[-2.4]^{* *}}\end{array}$ \\
\hline R-squared & 0.42 & 0.91 & 0.91 & 0.50 & 0.83 & 0.9 \\
\hline Period & 1980-90 & $1980-90$ & $1980-90$ & 1960-95 & $1960-95$ & $1960-95$ \\
\hline Model & (1) & (2) & (3) & (1) & (2) & (3) \\
\hline Constant & $\begin{array}{l}0.04 \\
{[1.11]}\end{array}$ & $\begin{array}{l}0.13 \\
{[2.17] *}\end{array}$ & $\begin{array}{l}0.16 \\
{[1.96]^{*}}\end{array}$ & $\begin{array}{l}0.1 \\
{[6.4]^{* * * *}}\end{array}$ & $\begin{array}{l}0.13 \\
{[3.57]^{* * * *}}\end{array}$ & $\begin{array}{l}0.13 \\
{[3.15]^{* *}}\end{array}$ \\
\hline Beta & $\begin{array}{l}0.002 \\
{[0.55]}\end{array}$ & $\begin{array}{l}0.014 \\
{[2.1] *}\end{array}$ & $\begin{array}{l}0.017 \\
{[1.89] *}\end{array}$ & $\begin{array}{l}0.01 \\
{[3.89] * * *}\end{array}$ & $\begin{array}{l}0.02 \\
{[2.66]^{* *}}\end{array}$ & $\begin{array}{l}0.02 \\
{[2.38]^{* *}}\end{array}$ \\
\hline Investment/GDP & & $\begin{array}{l}0.09 \\
{[1.39]}\end{array}$ & $\begin{array}{l}0.09 \\
{[1.26]}\end{array}$ & & $\begin{array}{l}0.087 \\
{[1.81]^{*}}\end{array}$ & $\begin{array}{l}0.09 \\
{[1.71]}\end{array}$ \\
\hline $\begin{array}{l}\text { Population } \\
\text { growth rate }\end{array}$ & & $\begin{array}{l}-0.05 \\
{[-0.55]}\end{array}$ & $\begin{array}{l}-0.05 \\
{[-0.55]}\end{array}$ & & $\begin{array}{l}-0.005 \\
{[-0.56]}\end{array}$ & $\begin{array}{l}-0.006 \\
{[-0.55]}\end{array}$ \\
\hline Inflation rate & & $\begin{array}{l}-0.006 \\
{[-2.92] * *}\end{array}$ & $\begin{array}{l}-0.005 \\
{[-2.07]^{*}}\end{array}$ & & $\begin{array}{l}-0.0003 \\
{[-2.04]^{*}}\end{array}$ & $\begin{array}{l}-0.0003 \\
{[-1.68]}\end{array}$ \\
\hline \multirow{2}{*}{$\begin{array}{l}\text { Gov. Expenditures/ } \\
\text { GDP }\end{array}$} & & 0.006 & -0.004 & & 0.015 & 0.017 \\
\hline & & {$[0.27]$} & {$[-0.15]$} & & [1.1] & {$[0.98]$} \\
\hline \multirow{2}{*}{ Regional dummy } & & -0.003 & -0.005 & & & 0.001 \\
\hline & & {$[-0.41]$} & {$[-0.54]$} & & & {$[0.16]$} \\
\hline R-squared & 0.023 & 0.52 & 0.54 & 0.63 & 0.79 & 0.79 \\
\hline
\end{tabular}

Note: Numbers in brackets are t-ratios. ${ }^{* *}, *^{*}, *$ indicate significance at the $1 \%, 5 \%$ and $10 \%$ level respectively.

variables enter the regressions with the theoretically correct expected sign, for example, investment has a positive estimated coefficient while population and inflation have a negative estimated coefficient. Increase in investment raises the capital per labor unit, therefore it is expected to increase the rate of growth of per 
capita GDP. Population growth reduces the capital per labor unit thus it is expected to reduce the rate of growth of the real per capita GDP. Similarly inflation is known to retard economic activity, thus it is expected to have a negative impact on the rate of growth of the real per capita GDP. The government to GDP ratio is expected to be inversely related to per capita $G D P$ growth, since very large government to GDP ratios tend to have a negative effect on economic activity of the private sector and reduce economic growth.

Table 3A. SUR Beta Estimates for Absolute and Conditional Convergence: Dependent Variable: Growth of Real Per Capita GDP

\begin{tabular}{|c|c|c|c|c|c|c|c|}
\hline 1960-1995 & Constant & Beta & $\begin{array}{c}\text { Invest/ } \\
\text { GDP } \\
\text { Ratio }\end{array}$ & $\begin{array}{c}\text { Population } \\
\text { Growth }\end{array}$ & $\begin{array}{c}\text { Inflation } \\
\text { Rate }\end{array}$ & $\begin{array}{c}\text { Gov/GDP } \\
\text { Ratio }\end{array}$ & $\begin{array}{c}\text { Regional } \\
\text { Dummy }\end{array}$ \\
\hline $\begin{array}{c}\text { Absolute } \\
\text { Convergence }\end{array}$ & $\begin{array}{c}0.16 \\
{[8.56]^{* * *}}\end{array}$ & $\begin{array}{c}0.015 \\
{[6.56]^{* * *}}\end{array}$ & & & & & \\
\hline $\begin{array}{c}\text { Conditional } \\
\text { Convergence }\end{array}$ & 0.2 & 0.021 & 0.11 & -0.03 & -0.006 & -0.026 & -0.006 \\
{$[9.04]^{* * *}$} & {$[8.52]^{* * *}$} & {$[3.5]^{* * *}$} & {$[-1.35]$} & {$[-6.93]^{* * * *}$} & {$[-2.68]^{* *}$} & {$[-2.02]^{* *}$} \\
\hline
\end{tabular}

Table 3B. SUR Estimates of Absolute and Conditional Convergence: Dependent Variable: Growth of Real Per Capita GDP

\begin{tabular}{|c|c|c|}
\hline $1960-1995$ & Beta & Number of Observations \\
\hline Absolute Convergence & $\begin{array}{c}0.01 \\
{[4.85]^{* * *}}\end{array}$ & $15,15,15,15$ \\
\hline Conditional Convergence & $\begin{array}{c}0.02 \\
{[6.2]^{* * *}}\end{array}$ & $12,15,15,15$ \\
\hline
\end{tabular}

Note: Numbers in brackets are $t$-statistics. $* * *, * *, *$ indicate significance at $1 \%, 5 \%$ and $10 \%$ level respectively. Due to lack of data, when the number of observation is 12 , excluded are France, Luxembourg and Portugal. The number of observations reported in Table 3B apply also to Table 3A for the two cases, of absolute and conditional convergence respectively.

The SUR method was also used to estimate these models. A system of simultaneous equations was estimated twice, first keeping all coefficients of the four subperiod regressions the same and second keeping only $\beta$ the same while allowing the coefficients of the other variables to differ. These results are reported in Tables 3A and 3B respectively. Both cases yielded $\beta$ values that were highly significant. In the first case, the values of $\beta$ are .015 and .021 for absolute and conditional convergence, respectively. In the second case, the $S U R$ method yielded plausible estimated $\beta$ coefficients of the magnitude of .01 and .02 for absolute and conditional convergence respectively. All the coefficients of the independent variables enter the regression with the theoretically correct expected sign. 
To improve the statistical fit of the regressions for the four sub-periods and the entire sample, the regression models were re-estimated using only the two most significant economic and the three socio-political and policy variables. The two economic variables were investment to GDP ratio and inflation. The three sociopolitical and policy variables were cabinet changes, riots and literacy rate. The NLS parameter estimates of this model are reported in Table 4. Clearly, $\beta$ is significant and positive in every sub-period except for the 1990-95 sub-period. The values of $\beta$ are in general higher than those reported in Table 2, and Tables 3A and 3B without the socio-political and policy variables.

Table 4. Conditional Convergence in the $E U$

\begin{tabular}{|c|c|c|c|c|c|}
\hline \multicolumn{7}{|l|}{ Regression for Real per Capita GDP Growth Across All 15 EU Countries } \\
\hline Variable & $1960-70$ & $1970-80$ & $1980-90$ & $1990-95$ & $1960-95$ \\
\hline Constant & 0.13 & 0.16 & 0.11 & 0.29 & 0.16 \\
\hline & {$[3.82]^{* * *}$} & {$[2.66]^{* *}$} & {$[1.5]$} & {$[1.38]$} & {$[3.09]^{* *}$} \\
\hline Beta & 0.02 & 0.023 & 0.017 & 0.04 & 0.02 \\
\hline & {$[3.93]^{* * *}$} & {$[2.76]^{* *}$} & {$[2.05]^{*}$} & {$[1.18]$} & {$[2.47]^{* *}$} \\
\hline Investment Ratio & 0.17 & 0.1 & 0.12 & 0.12 & 0.036 \\
\hline & {$[2.15]^{*}$} & {$[1.77]$} & {$[1.38]$} & {$[0.40]$} & {$[0.58]$} \\
\hline Inflation rate & 0.003 & -0.01 & -0.005 & -0.04 & -0.004 \\
\hline & {$[0.31]$} & {$[-2.4]^{* *}$} & {$[-1.9]^{*}$} & {$[-.80]$} & {$[-1.63]$} \\
\hline Cabinet change & 0.006 & 0.013 & 0.001 & -0.001 & 0.005 \\
\hline & {$[0.86]$} & {$[2.14]^{*}$} & {$[0.2]$} & {$[-0.04]$} & {$[0.87]$} \\
\hline Literacy Rate & 0.07 & 0.04 & 0.04 & 0.07 & -0.01 \\
\hline & {$[3.25]^{* *}$} & {$[1.26]$} & {$[0.75]$} & {$[0.46]$} & {$[-0.38]$} \\
\hline Riots & 0.001 & 0.001 & 0.0003 & -0.01 & -0.002 \\
\hline R-squared & {$[0.65]$} & {$[0.99]$} & {$[0.19]$} & {$[-1.23]$} & {$[-1.08]$} \\
\hline
\end{tabular}

Note: Numbers in brackets are $t$-statistics. $* * * * * *$ indicate significance at $1 \%, 5 \%$ and $10 \%$ level respectively.

Specifically the $\beta$ values of Table 4 are always higher from the estimated values of $\beta$ in the case of absolute convergence. For the entire sample, the value of $\beta$ is now .02 . This means a rate of convergence of $2 \%$ per annum. Such findings suggest that the speed of convergence among the $E U$ countries was lower because of the presence of differing economic, socio-political, and policy conditions among countries. A policy recommendation can be drawn from the above results. The $E U$ countries could converge at a faster rate if they could reduce economic and sociopolitical differences. This is exactly what the $E U$ common policies aimed to achieve. 
Table 5A. SUR Estimates for Absolute and Conditional Convergence: Dependent Variable: Growth of Real Per Capita GDP

\begin{tabular}{|c|c|c|c|c|c|c|c|}
\hline $1960-1995$ & Constant & Beta & $\begin{array}{c}\text { Invest/GDP } \\
\text { Ratio }\end{array}$ & $\begin{array}{c}\text { Inflation } \\
\text { Rate }\end{array}$ & $\begin{array}{c}\text { Literacy } \\
\text { Rate }\end{array}$ & $\begin{array}{c}\text { Cabinet } \\
\text { Changes }\end{array}$ & Riots \\
\hline $\begin{array}{c}\text { Absolute } \\
\text { Convergence }\end{array}$ & 0.16 & 0.015 & & & & & \\
{$[8.56]^{* * *}$} & {$[6.56]^{* * *}$} & & & & & \\
\hline $\begin{array}{c}\text { Conditional } \\
\text { Convergence }\end{array}$ & 0.15 & 0.023 & 0.11 & -0.006 & 0.05 & 0.006 & 0.0006 \\
{$[9.02]^{* * *}$} & {$[10.84]^{* * *}$} & {$[3.93]^{* * *}$} & {$[-8.17]^{* * *}$} & {$[4.53]^{* * *}$} & {$[2.38]^{* *}$} & {$[1.00]$} \\
\hline
\end{tabular}

Table 5B. SUR Estimates of Absolute and Conditional Convergence: Dependent Variable: Growth of Real Per Capita GDP

\begin{tabular}{|c|c|c|}
\hline $1960-1995$ & Beta & Number of observations \\
\hline $\begin{array}{c}\text { Absolute } \\
\text { convergence }\end{array}$ & 0.01 & $(15,15,15,15)$ \\
\hline Conditional & $.85]^{* * *}$ & $(13,15,15,13)$ \\
convergence & {$[9.11]^{* * *}$} & \\
\hline
\end{tabular}

Note: Numbers in brackets are $t$-statistics. $* * *, * *, *$ indicate significance at $1 \%, 5 \%$ and $10 \%$ level, respectively. When the number of observation is 13 , excluded are UK and Luxembourg for lack of data.

The SUR method was also used to estimate the model with the same five variables as a system of four equations corresponding to the four sub-periods. These results are reported in Tables 5A and 5B below when all coefficients are kept the same, and when all coefficients except $\beta$ are allowed to vary respectively.

As seen in Tables 5A and 5B there exists statistical evidence for $\beta$-convergence. We see in Table 5A that four out of the five explanatory variables are highly significant and have the correct theoretically expected sign. Both absolute and conditional convergence is supported by the two estimated SUR models. According to these results, absolute convergence amounts to 1.5 and 1.0 per cent per annum, while conditional convergence is 2.3 and 2.9 per cent per annum, respectively. Comparing the estimation results of the SUR method with those of the $N L S$, it is clear that the $\beta$ estimates are similar. There is, however, an improvement in the estimates of the coefficients of the explanatory variables with the SUR method in terms of statistical significance.

\section{Convergence Within and Between $E U$ Sub-groups}

In this section, the models of equations (1) and (2) were estimated for $E U 15$ and three other sub-groups of $E U$ countries: $E U 6, E U 9$, and $E U$-North. The latter group consists of all the $E U$ countries except the southern $E U$ members of Greece, 
Portugal, and Spain. EU-North was included to examine whether convergence also took place among European countries that were not members of the $E U$ during the period examined in this study. ${ }^{17}$

Both measures of convergence, absolute and conditional, were estimated for each of the three decades and for the one five-year sub-period, as well for the entire sample period. The model for conditional convergence includes the five explanatory variables discussed earlier. To save space we report only the SUR results for the entire sample period in Tables $6 \mathrm{~A}$ and $6 \mathrm{~B}$ below.

As seen in these results, there exists statistical evidence for both absolute and conditional convergence. However, some differences exist in the rates of conver-gence among the $E U$ sub-groups of countries. The entire group of the EU15 countries attained the lowest $\beta$ values for unconditional convergence, .015 and .01 according to the two SUR estimated models. The $E U 15$, however had a relatively high $\beta$ values for conditional convergence, .023 and .029 respectively, according to the two SUR methods. These results imply that there are substantial differences among this diverse group of countries. Hence, the conditioning factors are important and their inclusion in the regression increase the estimated $\beta$ coefficients substantially. On the other hand, the differences in the estimated $\beta$ values for the other $E U$ sub-groups, particularly $E U$ North and $E U 9$, corresponding to absolute and conditional convergence are very small.

Table 6A. SUR Estimates of Absolute and Conditional Convergence: Dependent Variable: Growth of Real per Capita GDP

\begin{tabular}{|c|c|c|c|c|c|}
\hline $1960-1995$ & & $E U 15$ & $E U 6$ & $E U 9$ & $E U-$ North \\
\hline Absolute Convergence & \multirow{2}{*}{ Beta } & $\begin{array}{c}0.015 \\
{[6.56]^{* * *}}\end{array}$ & $\begin{array}{c}0.024 \\
{[6.43]^{* * * *}}\end{array}$ & $\begin{array}{c}0.015 \\
{[5.23]^{* * *}}\end{array}$ & $\begin{array}{c}0.02 \\
{[6.28]^{* * *}}\end{array}$ \\
\hline Conditional Convergence & \multirow{2}{*}{ Beta } & $\begin{array}{c}0.023 \\
{[10.84]^{* * *}}\end{array}$ & $\begin{array}{c}0.026 \\
{[10.23]^{* * *}}\end{array}$ & $\begin{array}{c}0.021 \\
{[6.85]^{* * *}}\end{array}$ & $\begin{array}{c}0.022 \\
{[8.95]^{* * *}}\end{array}$ \\
\hline
\end{tabular}

Table 6B. SUR Estimates of Absolute and Conditional Convergence Dependent Variable: Growth of Real Per Capita GDP

\begin{tabular}{|c|c|c|c|c|c|}
\hline $1960-1995$ & & $E U 15$ & $E U 6$ & $E U 9$ & $E U$-North \\
\hline Absolute Convergence & Beta & $\begin{array}{c}0.01 \\
{[4.85]^{* * *}}\end{array}$ & $\begin{array}{c}0.026 \\
{[3.2]^{* * *}}\end{array}$ & $\begin{array}{c}0.013 \\
{[3.75]^{* * *}}\end{array}$ & $\begin{array}{c}0.015 \\
{[3.35]^{* * *}}\end{array}$ \\
\hline Conditional Convergence & Beta & $\begin{array}{c}0.029 \\
{[9.11]^{* * *}}\end{array}$ & $\begin{array}{c}0.008 \\
{[4.06]^{* * *}}\end{array}$ & $\begin{array}{c}0.018 \\
{[8.89]^{* * *}}\end{array}$ & $\begin{array}{c}0.022 \\
{[6.86]^{* * *}}\end{array}$ \\
\hline
\end{tabular}

Note: Numbers in brackets are $t$-statistics. $* * *, * * *$ indicate significance at $1 \%, 5 \%$ and $10 \%$ level respectively

\footnotetext{
${ }^{17}$ The countries, which joined in 1995 are: Sweden, Finland, and Austria.
} 
This is evidence that the economies of the $E U$-North and $E U 9$ sub-groups of countries, which also converged, are structurally similar.

These results suggest that approximately fifty years of common $E U$ policies intended to integrate the European economies were successful in achieving economic convergence.

The relation between the initial year real per capita GDP and the growth rate of each of the five $E U$ groups of countries was examined for the period 1960-1995. These $E U$ groups are $E U 6, E U 9, E U 12, E U 15$, and $E U$-South. The latter includes the four Mediterranean countries, Greece, Portugal, Spain and Italy. This relation was found strong, negative, and almost linear, as it was indicated in a scatter diagram, which is not shown here. This evidence suggests that when convergence exists, it is not lost even when high aggregation is applied to the data.

\section{Convergence in the World}

Figure 4 shows the coefficient of variation $(C V)$ of the real per capita $G D P$ of

Figure 4. Coefficient of Variation of Real Per Capita GDP in the World

Coefficient of Variation of Real Per Capita GDP in the World

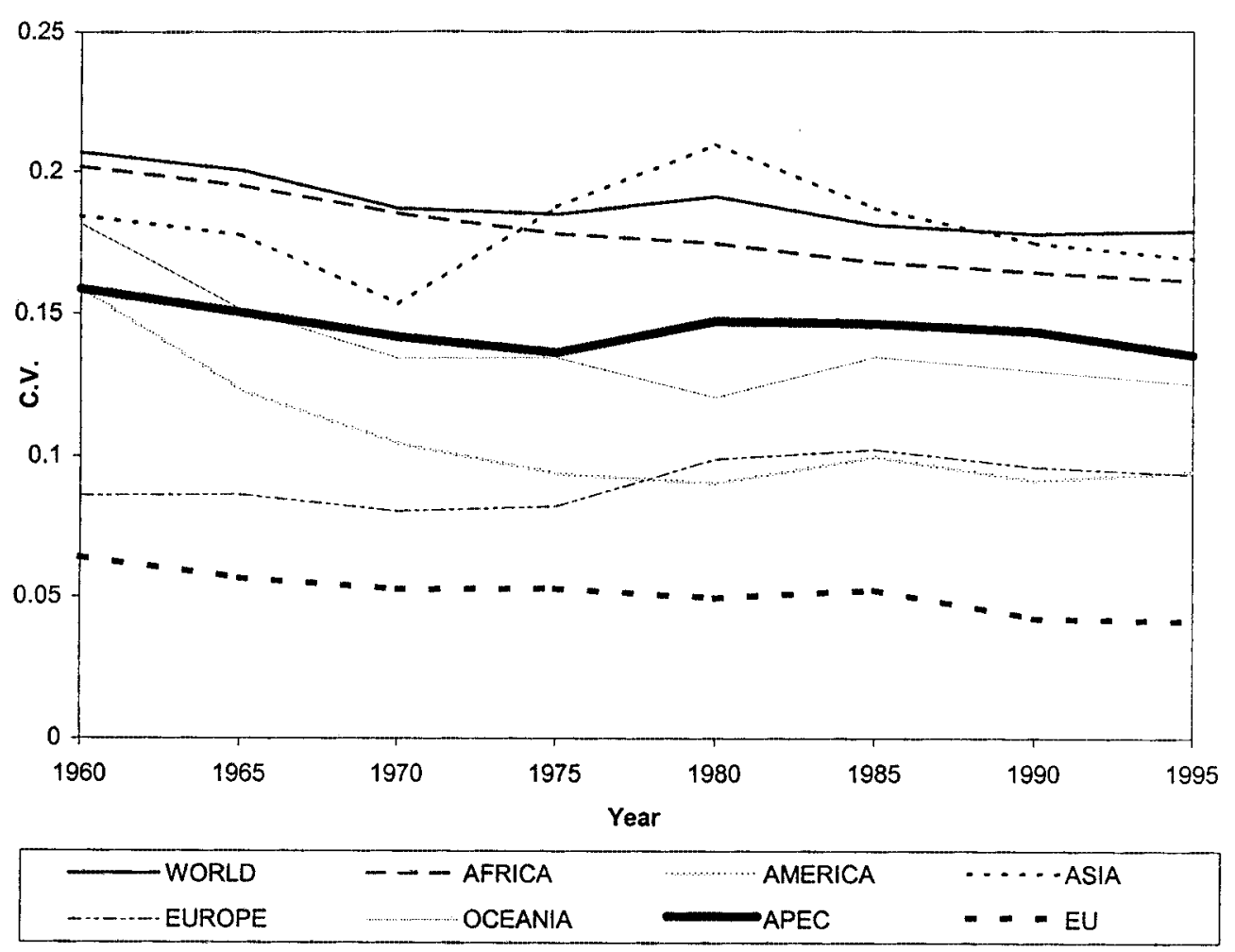


all fifteen $E U$ countries with the $C V$ of the real per capita $G D P$ of five continents and another trade bloc of countries. As noted earlier, a decline in the $C V$ for prolonged time indicates convergence whereas an increase in the $C V$ suggests divergence. The continents are Africa, Latin America, Asia, Europe, Oceania, and the trade bloc is the Asian Pacific Economic Cooperation Forum (APEC). The data used in the calculations of the $C V s$ are expressed in 1995 national currency units. It can be seen from this diagram that the $C V$ of the real per capita GDPs of the EU15 is the lowest one and it has been declining during the entire sample period (1960-1995). The group of countries with the second lowest $C V$ is Europe, which consists of EU15 and another set of thirteen countries most of which will join the $E U$ within the next few years. This finding is further evidence that economic integration can occur among a group of countries that jointly undertake coordinated economic policies that are given priority over national economic policies. This was the case for the $E U$ for the period 1960-1995.

\section{Conclusion}

This paper examined whether $E U$ countries have been successful in integrating their economies during the period 1960-1995. In particular, we studied whether there was a tendency for convergence of the real per capita GDP among the $E U$ countries. Two measures of economic convergence were utilized; the crosssectional standard deviation of the real per capita GDPs, $(\sigma)$ and the $(\beta)$ measure of convergence of the real per capita GDPs based on the neoclassical growth model. The empirical results suggest evidence of ongoing convergence among the $E U$ economies during the entire sample period with the exception of the subperiod 1980-1985.

When the 10-year sub-periods were employed, it was shown that convergence in the $E U$ was strong and uninterrupted. This study also examined convergence/ divergence within and between $E U$ sub-groups of countries. Convergence was supported between $E U$ sub-groups of countries and within each $E U$ sub-group but in different and explainable degrees. Comparing convergence among five continents, $E U 15$ and $A P E C$, we found that the $E U$ is the group of countries that succeeded in pursuing economic convergence during the last three and a half decades of 1960-1995. The study also revealed that existing economic, sociopolitical and policy differences among $E U$ member countries reduce the rate of convergence in the $E U$. It is difficult to pinpoint the exact reasons that contributed 
to convergence of the European Union.

International trade agreements spearheaded mainly by GATT promoted trade liberalization and global economic integration in the post World War II period. The $E U$ countries chose to pursue a faster path to economic integration among each other. To accomplish this, they formed a customs union and a common market, they also adopted common structural policies to promote harmonious economic development and attain economic convergence. The proximity and similarity of the $E U$ economies played a positive role in the European economic integration. The $E U$ is far from eliminating regional and national economic disparities, particularly in closing the gap in the real per capita GDP among member states. The formation of the European Monetary and Economic Union with the newly adopted common currency (the Euro) is the most recent and daring program that aims to promote further economic integration among the $E U$ countries.

\section{Acknowledgement}

Special thanks go to Alexander Zestos and Iris Price for typing and editing the manuscript. We are grateful to Professors Damodar Gujarati, Apostolos Serletis, Robert Winder, George Canavos, and Gemma Kotula and the session participants of the annual meetings of the Canadian Economic Association at the University of British Columbia, Vancouver, Canada, May 29-June 1, 2000 for their helpful and insightful comments. We are also especially thankful to the two anonymous referees and the editor of this Journal for constructive criticism and useful suggestions. The second and third authors are grateful for financial support provided by a Faculty Development Research Grant from Christopher Newport University and the Social Sciences and Humanities Research Council of Canada, respectively.

Received 27 December 2000, Accepted 15 February 2002

\section{References}

Armstrong, H.W. (1995), “An Appraisal of the Evidence from Cross-sectional Analysis of the Regional Growth Process within the European Union." In R. W. Vickerman, H. W. Armstrong eds. Convergence and Divergence Among European Regions In European Research in Regional Science, Vol. 5, London, Pion, pp. 41-65.

Austin, J.S. and Schmidt, J.R. (1998), "Convergence Amid Divergence in a Region" 
Growth and Change 29 (Winter), pp. 67-89.

Barro, R.T. (1991), "Economic Growth in a Cross Section of Countries" The Quarterly Journal of Economics 106 (May), pp. 407-443.

Barro, R. J. (1996), "Democracy and Growth" Journal of Economic Growth 1 (March), pp. 1-27.

Barro, R.J., and Sala-I-Martin, X. (1991), "Convergence Across States and Regions" Brooking Papers on Economic Activity 1, pp. 107-182(a).

Barro, R.J., and Sala-I-Martin, X. (1992), "Convergence” Journal of Political Economy 100 (2), pp. 223-251.

Barro, R.J., and Sala-I-Martin, X. (1995), Economic Growth, New York: McGraw-Hill.

Ben-David, D. (1993), "Equilizing Exchange: Trade Liberalization and Income Convergence" The Quarterly Journal of Economics 108 (August), 653-680.

Ben-David, D. and Loewy, M. B. (2000), "Knowledge Dissemination, Capital Accumulation, Trade, and Endogenous Growth" Oxford Economic Papers (52) (October) pp. 638-649.

Cheshire, P. and Carbonaro G. (1995), "Convergence/Divergence in Regional Growth Rates: An Empty Black Box?” In R.W. Vickerman, H. W. Armstrong eds. Convergence and Divergence Among European Regions European research in regional science. London, Pion 89-111.

Dewhurst, J. H. and Mutis-Gaitan, H. (1995), “ Varying Speeds of Regional GDP Per Capita Convergence in the European Union, 1981-91.” In R.W. Vickerman, H. W. Armstrong eds. Convergence and Divergence Among European Regions European research in regional science. London, Pion, pp. 22-39.

Easterly, W. and Levine, R. (1997), “Africas Growth Tragedy: Politics and Ethnic Divisions" The Quarterly Journal of Economics 107 (November) (4), pp. 1202-1250.

Evans, P. (1996), "Using Cross-Country Variances to Evaluate Growth Theories" Journal of Economic Dynamics and Control 20, pp. 1027-49.

Fagerberg, J. and Vespagen, B. (1996), "Heading for Divergence? Regional Growth in Europe Reconsidered” Journal of Common Market Studies 34 (September) (3), pp. 431-448.

Gastil, R.D. (1990), "The Comparative Survey of Freedom: Experience and Suggestions" Studies in Comparative Economic Development 25 (Spring) (1), pp. 25-50.

Giannias, D. and Liargovas, P. and Manolas, G. (1997), "Quality of Life Indices for Analyzing Convergence in the European Union” Regional Studies 33 (1), pp. 27-35.

Jacquemin, A. and Sapir, A. (1988), "European Integration or World Integration" Weltwischaftliches Archiv 124, pp. 127-39.

Knack, S. and Keefer, P (1997), "Does Social Capital Have an Economic Payoff? A Cross-Country Investigation” The Quarterly Journal of Economics 107 ( November) (4), pp. 1251-1288.

Koopmans, T. C. (1965), "On the Concept of Optimal Economic Growth" in The Econometric Approach to Developmental Planning. Amsterdam: North Holland.

Krugman, P. and Venables, T. (1990), "Integration and the Competitiveness of Peripheral 
Industry" In Bliss C. and Braga de Macedo, J. (eds.),Unity With Diversity in the European Economy: The Communitys Southern Frontier. Cambridge: Cambridge University Press, pp. 55-75.

Lloyd P. J. (1992), "Regionalization and World Trade" OECD Economic Studies 18, pp. 7-34.

Nevin, D. (1995), "Regional Convergence in the European Community" Journal of Common Market Studies 33 (March) (1), pp. 47-65.

Quah, D. (1993), "Empirical Cross-Section Dynamics in Economic Growth" European Economic Review 37, pp. 426-434.

Quah, D. (1993), "Galtons Fallacy and Tests of the Convergence Hypothesis" Scandinavian Journal of Economics 95 (4), pp. 427-43.

Ramsey, F. P. (1928), “A Mathematical Theory of Saving” Economic Journal 38 (December), pp. 543-59.

Romer, P. M. (1986), "Increasing Returns and Long-Run Growth" Journal of Political Economy 94 (5), pp. 1002-1037.

Sapir, A. (1992), "Regional Integration in Europe" The Economic Journal 102 (November), pp. 1491-1506.

Solow, R. M. (1956), "A Contribution to the Theory of Economic Growth" Quarterly Journal of Economics LXX, pp. 65-94.

Sala-I-Martin, X. (1996), "The Classical Approach to Convergence" The Economic Journal 106 (July), pp. 1019-1036.

Van der Laan L. (1995), "Cohesion Policies and Future Regional Demographic and Participation Changes in the European Union.” In R. W. Vickerman, H. W. Armstrong eds. Convergence and Divergence Among European Regions, European Research in Regional Science, Vol. 5, London, Pion, pp. 140-156. 